\title{
A POLÍTICA DE ACOLHIMENTO DE REFUGIADOS - CONSIDERAÇÕES SOBRE O CASO PORTUGUÊS
}

\author{
The refugees host policies - brief considerations \\ on the Portuguese case
}

\author{
Bruno Ferreira Costa* \\ Géssica Teles ${ }^{* *}$
}

\begin{abstract}
Resumo. A eclosão de conflitos armados e civis no Médio Oriente, bem como a expansão do autoproclamado Estado Islâmico provocou um fluxo considerável de refugiados com destino ao espaço comunitário europeu, sendo a maior vaga migratória desde a II Guerra Mundial. A atratividade do espaço europeu, associado às políticas de acolhimento, constitui o ponto de partida para esta análise que incide sobre os mecanismos de acolhimento registados pelo Estado Português. Através de um estudo iminentemente exploratório e recorrendo ao método de análise descritiva, optámos por analisar as estratégias de acolhimento, bem como os dados existentes sobre os processos em vigor em Portugal, considerando igualmente uma visão comparativa com os demais Estados-membros da União Europeia.
\end{abstract}

Palavras-chave: refugiados, políticas de acolhimento, migrantes involuntários, Portugal.

\begin{abstract}
The outbreak of armed and civil strife in the Middle East, as well as the expansion of the self-proclaimed Islamic State, has led to a considerable influx of refugees into the European Community space, the largest wave since the Second World War. The attractiveness of the European area, coupled with host policies, is the starting point for this analysis, which focuses on the reception mechanisms registered by the Portuguese State. Through an imminently exploratory study and using the descriptive analysis method, we opted to analyze the reception strategies as well as the existing data on the processes in force in Portugal, also considering a comparative view with the other Member States of the European Union.
\end{abstract}

Keywords: refugees, host policies, involuntary migrants, human rights, Portugal.

* Faculdade de Artes e Letras - Departamento de Comunicação e Artes. Universidade da Beira Interior. Covilhã, Portugal.

** Universidade da Beira Interior. Covilhã, Portugal. 


\section{Nota introdutória}

Os últimos anos são marcados pela emergência de um grande fluxo migratório com destino à União Europeia (U.E.), sendo que esse fluxo resultou, essencialmente, da emergência do conflito civil armado na Síria, na expansão do autoproclamado Estado Islâmico e na proliferação de conflitos nos países do norte de África.

Importa, neste contexto de concetualização, referir a importância da Convenção relativa ao Estatuto dos Refugiados (Convenção de Genebra de 1951) ${ }^{1}$ como mecanismo de enquadramento das situações suscetíveis a serem integradas no conceito de "refugiado". De um modo sintético, enquadram-se neste registo todos os indivíduos que sejam forçados a abandonar o seu país de origem face a perseguições por motivos de ordem religiosa, raça, nacionalidade, filiação a determinado grupo social ou político.

A definição imbrica diretamente com a problemática da defesa dos direitos humanos, sendo que a defesa desses direitos está na base do posicionamento dos países de acolhimento face a situações que se enquadram no registo de pedidos de asilo/estatuto de refugiado. Neste contexto de um elevado fluxo de refugiados, e face à proximidade geográfica e desenvolvimento económico e social, a U.E. tornou-se um polo atrativo para todos os que procuram um novo recomeço das suas vidas.

Esta nova vaga de refugiados tem colocado aos Estados europeus uma série de desafios, de ordem política, económica, social e cultural, sendo que a U.E. tem procurado um posicionamento comum (uma resposta conjunta) para maximizar a eficácia das políticas de acolhimento, o que não tem sido possível face ao posicionamento de determinados Estados na rejeição do programa de distribuição de refugiados pelo continente europeu.

O presente trabalho incide sobre o posicionamento e as estratégias de integração adotadas pelo Estado Português, mais concretamente as verificadas no XXI Governo Constitucional (2015-) e que consubstanciam um posicionamento favorável à integração dos refugiados no tecido social português, sendo que em virtude deste período o trabalho incide sobre uma vertente exploratória.

\section{O estatuto de refugiado e a inviolabilidade dos direitos humanos}

A migração dos povos acompanha a própria evolução humana. De facto, desde sempre se verificaram movimentos migratórios, causados por questões económicas, sociais, culturais, bélicas, políticas e ambientais. A recente vaga de refugiados está relacionada sobretudo com a guerra civil na Síria, sendo

1 Disponível em: < http://www.unhcr.org/protect/PROTECTION/3b66c2aa10.pdf>. Acesso em: 01.07.2017. 
que milhares de migrantes têm procurado atingir solo europeu através do Mar Mediterrâneo ou da rota dos Balcãs.

Após o início da recuperação da grave crise económica que assolou a Europa desde 2008, os Estados Europeus depararam-se com os desafios e os problemas associados a um volume anormal de migrações. Ao contrário dos "refugiados clássicos" da década de 1990, acolhidos essencialmente por motivos de perseguição política, a presente vaga de refugiados surge como uma tentativa de fugir de um cenário de guerra violenta e perseguição vivido em todo o território sírio.

Estamos perante um conceito abrangente, resultado do alargamento de uma visão clássica sobre o fenómeno dos refugiados, nomeadamente a premissa de incluir novas causas na base do movimento migratório. Nesse âmbito, constata-se, muitas vezes, a referência a "migrantes forçados ou involuntários", sendo que nesta classificação seria possível incluir, por exemplo, os migrantes por razões económicos, o que não constituiu necessariamente uma premissa para a atribuição do estatuto de refugiado. As desigualdades económicas e sociais, mesmo que não imbrincadas com um processo de perseguição, podem constituir a base de uma migração forçada, bem como as migrações resultantes de problemas ambientais. De facto, "a migração forçada ocorre devido a uma série de fatores, incluindo a perseguição, os desastrais naturais e industriais, projetos de desenvolvimento, degradação ambiental, guerra e conflito" ${ }^{2}$.

Alguns autores ${ }^{3}$ advogam, inclusivamente, uma transferência ao nível dos estudos sobre refugiados para os estudos sobre as migrações forçadas (cujo âmbito é mais amplo), focados num reforço do humanitarismo político.

No entanto, importa verificar que a atual crise dos refugiados não resulta apenas dos acontecimentos no Médio Oriente ou no continente Africano. De facto, "a verdadeira crise não é baseada em números ou mesmo no grau de

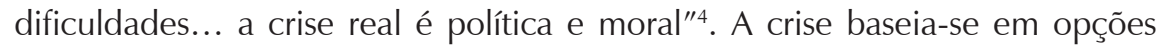
políticas e na forma como os problemas são comunicados e transmitidos à sociedade, ora promovendo o medo face à diferença, ora salientando os benefícios da integração e de uma sociedade multicultural.

Considerando o início desta vaga de refugiados, Michael Marrus 5 identifica três aspetos centrais para caracterizar a atual vaga de refugiados: o crescimento exponencial do número de refugiados, principalmente originários de África e do Médio Oriente, a maior duração do período de exílio dos refugiados (o que coloca a questão sobre a eficiência do sistema e a permanência por longos

\footnotetext{
2 MASON, Elisa. Forced Migration Studies, p. 241.

3 CHIMNI, Bhupinder. The Birth of a 'Discipline': From Refugee to Forced Migration Studies.

4 ADELMAN, Howard. The refugee crisis, p. 1.

5 MARRUS, Michael. The Forty Years Crisis: Refugees in Europe, 1919-1959, Conference Page.
} 
períodos dos refugiados em campos de acolhimento) e a flexibilidade entre esta nova vaga de refugiados e um novo conceito de apátridas, que extravasa a simples inexistência de um vínculo legal (nacionalidade) entre um indivíduo e um determinado Estado ${ }^{6}$.

O ritmo de crescimento do número de refugiados é acompanhado pela multiplicação das rotas migratórias, tendo a Agência Europeia da Guarda de Fronteiras e Costeira (Frontex) identificado em 2017 oito rotas: África Ocidental; Mediterrâneo Ocidental; Mediterrâneo Central; Apúlio e Calábria; Balcãs Ocidentais; Mediterrâneo Oriental; fronteiras orientais e o percurso circular da Albânia para a Grécia ${ }^{7}$.

O aumento do número e da diversidade das rotas migratórias, utilizadas pelos refugiados, tem gerado um elevado fluxo de acolhimento em vários Estados europeus, sendo que a predisposição dos governos nacionais em acolher refugiados é bastante díspar, o que resulta da ausência de uma política comunitária comum. A emergência destes novos fluxos tem gerado um conjunto de alterações profundas nas sociedades de acolhimento, visíveis por exemplo a nível demográfico, cultural e económico, mas também ao nível do surgimento de movimentos nacionalistas e de extrema-direita, contrários a uma política de "portas abertas" aos refugiados e aos imigrantes.

O presente estudo tem por base a migração forçada e, dentro deste âmbito, a migração causada pela necessidade de preservar a vida face a ameaças justificadas pelas diferenças religiosas, de raça, de nacionalidade, pertença a grupo social e/ou político, precisamente as bases da Convenção de Genebra de 1951. No entanto, esta classificação não seria suficiente para espelhar a atual realidade do movimento de refugiados que engloba igualmente indivíduos que procuram o abrigo de Estados terceiros face a ameaças que colocam em causa a sua vida (por exemplo, em cenários de guerra civil e/ou violência generalizada ou perante violações sistemáticas dos direitos humanos).

Estamos perante a necessidade de englobar as migrações internacionais numa perspetiva assistencialista e de empoderamento dos indivíduos (efetiva

6 De facto, tendo presente que a apatridia remete para a situação de indivíduos que não são considerados nacionais de nenhum Estado, verifica-se a possibilidade dos apátridas serem igualmente reconhecidos como refugiados. A perda de nacionalidade causa um impacto significativo na vida das pessoas, nomeadamente ao nível da proteção dos seus direitos, sendo que perante esta dupla situação (apátrida e refugiado), mesmo que o Estado não reconheça as condições para a atribuição do estatuto de refugiado, o cidadão estará protegido pelas normas vigentes da Convenção sobre o Estatuto dos Apátridas (caso o Estado seja signatário). Por sua vez, a apatridia, entendida como fenómeno de massa, surge, invariavelmente associada a situações de perseguição/descriminação, correspondendo a alguns dos critérios para a atribuição do estatuto de refugiado (LISOWSKI, Telma. A Apatridia e o "Direito a ter Direitos": Um Estudo sobre o Histórico e o Estatuto Jurídico dos Apátridas).

7 Disponível em: <http://frontex.europa.eu/trends-and-routes/migratory-routes-map/>. Acesso em: 17.07.2017. 
integração dos mesmos nas sociedades de acolhimento), pelo que é necessária a "elaboração de instrumentos novos de intervenção humanitária"8.

Qualquer análise da atual crise dos refugiados deve ter presente o conjunto de direitos fundamentais dos indivíduos, tidos como direitos universais inalienáveis. No entanto, convém referir que grande parte dos conflitos na base de movimentos migratórios surge em países sem expressão internacional (atente-se ao critério internacional de seleção de notícias), o que pode estar na base de alguma inação dos restantes Estados perante estes conflitos ${ }^{9}$.

O reconhecimento do estatuto de refugiado é um processo moroso e complexo, pouco adequado às necessidades efetivas dos requerentes de asilo, uma vez que o cenário de retorno ao país de origem pode colocar em perigo a vida destes indivíduos. Com base nesta premissa, importa referir o reduzido número de estudos académicos e relatórios sobre os indivíduos que viram o seu requerimento de asilo recusado, nomeadamente as condições associadas ao regresso ao país de origem.

Os Estados desempenham neste processo um papel primordial no estabelecimento das políticas de acolhimento aos refugiados, bem como nas políticas que visem a efetiva integração dos mesmos na sociedade, considerando que o combate inicial incide, igualmente, sobre as perspetivas discriminatórias, racistas exenófobas. Este contributo estatal é delineado precisamente pelo poder executivo, em parceria com as diversas organizações não-governamentais e com a sociedade civil globalmente considerada. O primeiro objetivo passa por garantir a proteção e a assistência com o intuito de assegurar um conjunto de direitos básicos, precisamente os direitos inalienáveis, ou seja, não transferíveis e não questionáveis ${ }^{10}$.

Esta abordagem inclui os direitos humanos, nomeadamente o que John Locke denominava de direitos naturais e inalienáveis dos homens: direito à vida, à liberdade e o direito à propriedade ${ }^{11}$, sendo os mesmos aprofundados na Declaração Universal dos Direitos Humanos - DUDH (1948) ${ }^{12}$. O princípio da conceção do estatuto de refugiado passa por garantir estes direitos a todos indivíduos, independentemente da respetiva origem. Este enquadramento legal foi decisivo para a emergência e afirmação dessa perspetiva universal, tendo a mesma sido baseada nos princípios que nortearam a revolução francesa no século XVIII (liberté, egalité, fraternité).

8 SOUSA, Lúcio. A crise global de refugiados: (in)visibilidade e memória das migrações forçadas, p. 76.

9 JUBILUT, Liliana. O Direito internacional dos refugiados e a sua aplicação no orçamento jurídico brasileiro.

${ }^{10}$ MORÊZ, Francielli. O refúgio e a questão da identificação oficial dos refugiados no Brasil.

${ }^{11}$ LOCKE, John. Segundo tratado sobre o governo civil: ensaio sobre a origem, os limites e os fins verdadeiros do governo civil - e outros escritos.

12 Disponível em: <http://www.ohchr.org/EN/UDHR/Documents/UDHR_Translations/por.pdf>. Acesso em: 02.07.2017. 
Com base nos princípios elencados na DUDH importa referir o artigo 140, que estabelece que "todo o ser humano, vítima de perseguição, tem o direito de procurar e de gozar de asilo em outros países". Tal não significa uma obrigatoriedade dos Estados na atribuição do estatuto de refugiado, uma vez que esta prerrogativa continua a ser um exclusivo de cada Estado e na qual se aplica a legislação nacional.

O procedimento para a conceção ou recusa do pedido de asilo tem gerado múltiplas interpretações no seio da U.E., nomeadamente ao nível do procedimento de recolocação dos refugiados que têm chegado ao território grego e italiano, uma vez que estes países têm sido a "porta de entrada" da maioria dos refugiados nos últimos anos. A opção tem sido a distribuição destes refugiados pelos restantes países da U.E., num acordo que visa a promoção da solidariedade dos Estados-membros.

Através da classificação apresentada por Renata Pierin podemos identificar cinco tipologias de indivíduos que migram de forma forçada e involuntária: os requerentes de asilo; os refugiados (beneficiando da atribuição deste estatuto); os deslocados no seio do mesmo país; os apátridas (que se apresentam sem qualquer vínculo jurídico a um Estado) e os asilados ${ }^{13}$. Ao socorrermo-nos da legislação internacional constatamos que os direitos dos refugiados estão abrangidos na Convenção de Genebra, na Convenção da Organização da Unidade Africana $(\mathrm{OUA})^{14}$ e na Declaração de Cartagena ${ }^{15}$.

A importância destes documentos deriva essencialmente do seu cariz universal e do número de países signatários das referidas declarações, o que permite criar um padrão de ação a nível internacional e garantir denominadores comuns na forma de acolhimento dos refugiados, independentemente da localização geográfica. Desse padrão de ações salienta-se as definidas pela Organização das Nações Unidas para a Educação, a Ciência e a Cultura (UNESCO), nomeadamente a afirmação dos direitos humanos como universais e inalienáveis; a não discriminação dos refugiados face a outros migrantes ou cidadãos nacionais; a aplicabilidade das normas internacionais de trabalho a todos os indivíduos e a premissa de que todos os que procuram proteção internacional face a ameaças à sua vida devem poder solicitar asilo.

A atribuição do estatuto de refugiado permite assegurar a proteção dos indivíduos envolvidos, a assistência económica, médica e social e a integração, objetivo a ter em consideração em qualquer processo de acolhimento ${ }^{16}$. A

\footnotetext{
13 PIERIN, Renata. Refugiados no mundo contemporâneo: breves considerações.

${ }^{14}$ Disponível em: <http://www.cidadevirtual.pt/acnur/acn_lisboa/e-oua.html>. Acesso em: 20.07.2017.

15 Disponível em: <http://www.acnur.org/t3/fileadmin/Documentos/portugues/BD_Legal/Instru mentos_Internacionais/Declaracao_de_Cartagena.pdf > . Acesso em: 17.08.2017.

16 JUBILUT, op. cit.
} 
intransigente defesa dos direitos humanos está, deste modo, intrinsecamente ligada à aprovação dos pedidos de asilo, sendo que este processo é o resultado da "liberdade do homem e da necessidade de protegê-lo contra o arbítrio e a violência"17.

Estamos perante um quadro complexo, marcado pelo receio de alguns governantes de adotar uma política de maior flexibilidade e abertura face aos movimentos migratórios em virtude das pressões das respetivas sociedades nacionais. O incremento do apoio popular a partidos anti-imigração e de extrema-direita é um dos condicionantes mais relevantes na análise dos programas políticos atuais e da forma como os governantes agem relativamente às questões das migrações. Por outro lado, o aumento do número de atentados terroristas em solo europeu tem influenciado a forma como os atores políticos agem perante a crise de refugiados (adotando posturas mais protecionistas e defensivas), perante a tentativa de alguns partidos de estabelecerem uma relação causa-efeito entre as migrações e o terrorismo ${ }^{18}$.

$\mathrm{O}$ enquadramento efetuado permite-nos avançar para a análise das políticas de acolhimento adotadas no espaço comunitário europeu, com um especial destaque para o caso português e tendo presente que a ação dos Estados deve incidir sobre a vertente assistencialista e protecionista face aos refugiados, mas igualmente sob uma vertente formativa junto da sociedade civil.

\section{A política de acolhimento de refugiados na Europa}

A emergência de múltiplas rotas de migração em solo europeu, aliado ao conflito na Síria e em diversos países Africanos, provocou, desde o início da presente década, um aumento significativo do número de refugiados a chegar à Europa, principalmente através da rota do Mar Mediterrâneo, tendo como destino a Grécia e a Itália.

Os sucessivos casos de naufrágios e afogamentos no Mar Mediterrâneo e a projeção internacional que estas mortes tiveram, impulsionaram os líderes políticos europeus a agir para fazer face a esta crise dos refugiados. Perante o maior fluxo migratório registado na Europa desde a II Guerra Mundial ${ }^{19}$ verificou-se a necessidade de adotar um plano comum, abrangente, que pudesse fazer face ao drama dos refugiados. No entanto, a dimensão do problema e a ausência de consenso entre os 28 Estados-membros motivou acérrimas discussões em torno da implementação de um plano comum de acolhimento de refugiados.

\footnotetext{
17 FERNANDES, Carlos. Do asilo diplomático, p. 147.

${ }^{18}$ Disponível em: <https://www.reuters.com/article/us-europe-attacks-idUSKBN19X1QO>. Acesso em: 19.07.2017.

${ }^{19}$ METCALFE-HOUGH, Victoria. The migration crisis? Facts, challenges and possible solutions. A policy brief.
} 
O atual contexto migratório, embora atenuado face ao pico verificado em 2015 e 2016, continua a ser acentuado, sendo oriundo essencialmente de países envolvidos em guerras civis e conflitos internos, como o Afeganistão, a Eritreia, a Nigéria, a Síria, o Sudão, o Sudão do Sul e a Tunísia, o que despoletou uma série de novos desafios para os governos e as sociedades europeias, bem como colocou a questão dos refugiados na agenda mediática e política ${ }^{20}$.

Através do relatório anual do ACNUR referente ao ano de $2016^{21}$ constata-se que existiam mais de 22 milhões de refugiados, dos quais 17.2 milhões sob o registo do Alto Comissariado das Nações Unidas para os Refugiados, sendo cerca de metade oriundos da Síria, Afeganistão e Sudão do Sul.

No final de 2016 a Europa acolhia mais de 5 milhões de refugiados, no entanto cerca de 2.8 milhões estavam registados na Turquia, de um total mundial superior a 17 milhões de refugiados. Ou seja, a Europa acolhia cerca de $30 \%$ do total de refugiados registados. O elevado número de refugiados não constitui o único desafio aos governantes europeus, sendo de destacar a multiplicação das rotas migratórias como um obstáculo à adoção de medidas preventivas e de ação perante o drama dos refugiados. O perigo associado a algumas dessas rotas, bem como a inclusão em massa de mulheres, crianças e pessoas idosas nas travessias veio agravar os riscos inerentes a qualquer processo de fuga ${ }^{22}$, sendo que muitas vezes as travessias são organizadas por grupos criminosos e através de embarcações desadequadas e sobrelotadas.

A esta complexidade acresce a ausência de uma posição comum por parte dos Estados-membros da U.E., principalmente com algumas resistências no bloco de leste à adoção de uma estratégia comum de recolocação de refugiados em todo o espaço comunitário ${ }^{23}$.

Importa referir que os ciclos eleitorais desempenham nesta estratégia um papel decisivo, uma vez que os líderes europeus pautam a respetiva ação com base na necessidade de serem reeleitos, sendo que o crescimento da extrema-direita em diversos países, bem como as mudanças de discurso verificadas em partidos pertencentes ao arco de governação, tradicionalmente mais moderados, motivou a adoção de um discurso mais restrito em relação às questões das migrações.

A ação dos dirigentes europeus surge impulsionada ora pela mediatização das mortes registadas nas rotas migratórias, ora pela ação de dirigentes europeus que consideram que a U.E. tem uma responsabilidade acrescida na

\footnotetext{
${ }^{20}$ SAMPAIO, Vera. Uma política europeia para as migrações?

${ }^{21}$ Disponível em: <http://www.unhcr.org/statistics/unhcrstats/5943e8a34/global-trends-forceddisplacement-2016.html> . Acesso em: 22.10.2017.

${ }^{22}$ METCALFE-HOUGH, op. cit.

${ }^{23}$ SAMPAIO, op. cit.
} 
defesa dos direitos humanos. Importa ter presente que o pico da crise dos refugiados surgiu num momento em que a Europa ainda respondia à forte crise económica iniciada em 2008 e que marcou, de forma indelével, a estrutura social de diversos Estados europeus, nomeadamente Portugal, face à intervenção económica do Fundo Monetário Internacional, do Banco Central Europeu e da Comissão Europeia.

Estamos perante um debate central na análise da capacidade de resposta dos Estados europeus e da constatação do grau de aceitabilidade das sociedades europeias a um maior fluxo de imigrantes e de refugiados. De facto, em períodos de recessão económica, com elevados índices de desemprego, assiste-se a uma maior preocupação face às questões da segurança, da estabilidade dos empregos, da sustentabilidade do Estado Social e da proteção das fronteiras ${ }^{24}$.

Perante a edificação de diversos campos de refugiados e a incapacidade demonstrada pelos Estados Europeus de acolheram o fluxo migratório registado desde 2015, impõe-se a adoção de um canal migratório legal e que permita o transporte dos refugiados de forma segura e digna.

Numa análise genérica às condições das travessias dos refugiados e aos planos iniciais de acolhimento constata-se a existência de diversas debilidades, nomeadamente na tentativa de garantir o acesso a condições condignas de habitação, alimentação, acesso a cuidados de saúde e oportunidades de integração nas comunidades de acolhimento ${ }^{25}$.

O legado humanista da Europa, bem como os progressos efetuados ao nível da defesa dos direitos humanos e do respeito pela individualidade de cada cidadão implica a existência de uma "obrigação moral" na resolução desta crise. Os valores fundacionais da U.E. exigem um plano coerente e que abranja todas as dimensões (políticas, éticas, culturais, morais, sociais, humanitárias) no acolhimento a refugiados.

No entanto, a tentativa de adotar um programa continental de acolhimento de refugiados não obteve o apoio de todos os Estados-membros. Em setembro de 2015, aquando da reunião dos Ministros do Interior da U.E., quatro Estados Europeus (Hungria, República Checa, República Eslovaca e Roménia) opuseram-se à recolocação de 160 mil refugiados em todo o espaço comunitário. Importa referir que ao abrigo dos estatutos de pertença à U.E., o Reino Unido e a Irlanda não foram abrangidos por esta medida, podendo, a título voluntário, optar por integrar o processo de acolhimento de refugiados.

Esta oposição tem sido salientada nos diversos relatórios produzidos pela Comissão Europeia sobre o processo de recolocação dos refugiados, tendo

\footnotetext{
${ }^{24}$ SAMPAIO, op. cit.

${ }^{25}$ GUILD, Elspeth, COSTELLO, Cathryn, GARLICK, Madeline, MORENO-LAX, Violeta. The 2015 Refugee Crisis in the European Union.
} 
o primeiro relatório sido produzido em março de $2016^{26}$. Um dos principais alertas refere-se ao número reduzido de pedidos de recolocação efetuado pelos Estados-membros, bem como a morosidade destes processos, conduzindo à multiplicação de situações de carência e violação dos princípios adstritos à aplicação da Convenção de Genebra.

De um modo genérico, e antes de observamos a especificidade do caso português, importa referir que o último relatório produzido pela Comissão Europeia $^{27}$ constata que nos primeiros seis meses de 2017 foram recolocados mais de 10 mil refugiados, num claro aumento face ao período homólogo em 2016. No entanto, este esforço tem sido produzido sem o contributo da Hungria e da Polónia (países que não acolheram qualquer refugiado) e, mais recentemente, da República Checa que não acolhe qualquer refugiado desde agosto de 2016.

O acordo para a recolocação dos refugiados firmado em 2015 estipulava a necessidade de agir no apoio aos dois países considerados como "portas de entrada" da mais recente vaga de refugiados: a Itália e a Grécia. De facto, estes Estados, pela localização geográfica, têm recebido milhares de refugiados, não tendo capacidade para processar o seu acolhimento.

No último relatório a Comissão Europeia destacava o facto de países como a Estónia, a Finlândia, a Letónia, a Lituânia, o Luxemburgo, Malta, a Noruega (mesmo não pertencendo à U.E., o Estado norueguês integra este processo) e Portugal estarem perto de atingir as respetivas quotas de recolocação, sendo que em relação aos refugiados registados em Itália apenas a Alemanha, a Finlândia, a Holanda, o Luxemburgo e Malta atingem números positivos.

Ao nível deste processo, a Comissão Europeia tem alertado Estados como a Áustria, a Bulgária, a Hungria, a Polónia, a República Checa e a República Eslovaca para a necessidade de envidarem esforços no sentido de procederem ao cumprimento das quotas atribuídas aos respetivos países.

Outra das preocupações prende-se com a autonomia de cada Estado no delinear das políticas de acolhimento, sendo que a existência de preferências no processo de acolhimento viola o princípio da igualdade no tratamento de refugiados. A recusa em receber refugiados do sexo masculino ou de determinada nacionalidade constitui exemplos concretos de práticas adotadas por alguns Estados, o que permite atestar a incapacidade de afirmação de uma resposta global da U.E. a esta problemática.

${ }^{26}$ Disponível em: <https://ec.europa.eu/transparency/regdoc/rep/1/2016/EN/1-2016-165EN-F1-1.PDF>. Acesso em: 20.08.2017.

27 Relatório disponível em: <https://ec.europa.eu/home-affairs/sites/homeaffairs/files/what-wedo/policies/european-agenda-migration/20170613_thirteenth_report_on_relocation_and_ resettlement_en.pdf>. Acesso em: 21.08.2017. 
A ausência de um caminho comum é igualmente evidente na estratégia em torno do acordo efetuado com a Turquia relativamente ao processo de reencaminhamento de refugiados que cheguem a território grego de forma ilegal para a Turquia. A medida visava essencialmente permitir que por cada refugiado reencaminhado para a Turquia a U.E. comprometia-se a acolher um refugiado sírio vindo diretamente da Turquia, sendo que todos os custos do processo seriam custeados pela U.E. ${ }^{28}$.

A visão mercantilista deste acordo foi severamente criticada por diversas organizações internacionais, tendo o próprio ACNUR se excluído de participar na gestão deste processo, bem como a Amnistia Internacional e os Médicos Sem Fronteiras. A principal acusação residia na incapacidade do Estado grego conseguir determinar que os refugiados reencaminhados para a Turquia fossem efetivamente ilegais e não correriam perigo de vida aquando do encaminhamento para a Turquia.

O caminho sinuoso seguido pelas estruturas e governos comunitários, aliado à gravidade da situação vivida pelos refugiados, constitui um dos mais sérios desafios para a construção do projeto europeu. Poderão os valores europeus vingar quando os pilares da solidariedade e da defesa da vida humana são colocados em causa pelas elites políticas?

\section{Portugal - integrar sob o manto da invisibilidade}

O caminho delineado pelas instituições europeias relativamente ao processo de acolhimento de refugiados foi globalmente bem recebido pelas forças políticas nacionais. De facto, considerando os partidos com assento parlamentar não se verificou qualquer oposição relativamente ao plano de acolher uma parcela do total dos 160.000 refugiados integrados no plano inicial de recolocação. Numa fase inicial Portugal comprometeu-se a receber cerca de 4.400 refugiados, sendo que até fevereiro de 2017 Portugal havia recebido apenas 1.000 refugiados, ou seja, 22\% da quota expectável.

O acordo delineado pela Comissão Europeia implica uma vertente "impositiva" face aos destinos atribuídos aos refugiados, o que coloca em discussão a questão dos direitos dos refugiados de selecionarem o destino no qual pretendem requerer o pedido de asilo. Este fenómeno tem provocado um elevado número de "desistências voluntárias" no quadro dos programas de acolhimento, questão que é transversal a diversos países, sendo que no caso português as estimativas apontam para cerca de $40 \%$ de refugiados que abandonaram o país, migrando para países como a França e Alemanha, que constituem destinos preferências ${ }^{29}$.

${ }^{28} \mathrm{O}$ acordo pode ser consultado em: <http://www.consilium.europa.eu/pt/press/pressreleases/2016/03/18-eu-turkey-statement/> . Acesso em: 19.08.2017.

${ }^{29}$ Ver: <http://sicnoticias.sapo.pt/especiais/crise-migratoria/2017-04-24-Mais-de-40-dos-refugiad os-acolhidos-por-Portugal-ja-abandonaram-o-pais>. Acesso em: 22.08.2017. 
O objetivo da presente investigação passa por analisar o programa de acolhimento de refugiados do Estado Português, bem como as estratégias de integração adotadas no sentido de efetivar o envolvimento dos refugiados na sociedade portuguesa. Considerando que o programa de acolhimento se encontra em curso, a presente investigação caracteriza-se por ser uma abordagem exploratória ao fenómeno da integração dos refugiados, num contexto em que o alargamento das fronteiras, o aumento do fenómeno migratório e a debilidade do Estado social, aliado à crise demográfica na Europa, colocam a U.E. num limbo de decisões em torno das opções políticas, económicas e sociais.

Face ao carácter exploratório da investigação, bem como o foco no caso português, iremos recorrer à análise descritiva para analisar a forma como o Estado português se encontra a estruturar a resposta à crise dos refugiados. Com efeito, o recurso à análise descritiva permite a interpretação dos factos sem a interferência do investigador, garantindo um caminho de cientificidade associado ao processo de investigação ${ }^{30}$.

Com base nesta premissa, procuraremos verificar de que modo o governo português tem participado na estratégia comunitária de acolhimento de refugiados e qual o impacto deste processo na sociedade portuguesa, considerando, inclusivamente, o esforço desenvolvido por diversas autarquias de menor dimensão para receber e integrar comunidades de refugiados. Poderá esta recolocação no interior do país e fora dos grandes centros urbanos estar na base do número de abandonos registados? Poderá esta tentativa de repovoar o interior através do programa de refugiados constituir um entrave à efetiva criação de oportunidades de integração, considerando as dimensões culturais, sociais, desportivas e laborais que os grandes centros urbanos disponibilizam? De que modo as sociedades de acolhimento poderão participar neste processo de integração, considerando que a vertente normativa ou legislativa não é suficiente para garantir o sucesso das políticas de acolhimento?

No que diz respeito ao primeiro ponto, importa referir que o atual executivo demonstrou desde o início do processo uma grande abertura para acolher o maior número de refugiados possível, ultrapassando a quota inicialmente prevista ${ }^{31}$. O foco desta disponibilidade prendia-se com o objetivo de acolher um elevado número de estudantes universitários, estudantes do ensino vocacional e refugiados qualificados para trabalhar na agricultura e domínios da floresta.

\footnotetext{
${ }_{30}$ BARROS, Aidil, LEHFELD, Neide. Fundamentos de Metodologia Científica.

${ }^{31}$ Informação disponível em: <http://www.tsf.pt/politica/interior/portugal-disponivel-parareceber-cerca-de-dez-mil-refugiados-5038144.html>. Acesso em: 04.08.2017.
} 
No entanto, o número de refugiados dispostos a vir para Portugal não acompanha esta disponibilidade de acolhimento demonstrada pelo país, sendo que o processo de distribuição de refugiados realizado pelas autoridades gregas e italianas tem sido criticado pela morosidade e complexidade do mesmo, o que pode influenciar a celeridade no processo de acolhimento.

Importa referir que desde o início do programa mais de 100 instituições e 140 autarquias demonstraram disponibilidade em acolher refugiados, num número que ultrapassa claramente o fluxo de refugiados que o país se encontra a receber. Este processo tem o contributo do Conselho Português para os Refugiados (CPR) e da Plataforma de Apoio aos Refugiados (PAR) que permite o envolvimento do cidadão comum no processo de acolhimento e apoio à integração.

Mesmo ao nível da distribuição de refugiados a nível nacional, poderá existir alguma preferência dos refugiados pelos grandes centros urbanos. De facto, dois terços dos refugiados em todo o mundo vivem em zonas urbanas, caracterizadas por uma maior diversidade cultural e pela multiplicação das oportunidades de integração (económicas, laborais, culturais e sociais).

Esta disponibilidade da sociedade civil (instituições) e das autarquias locais constitui um ponto central na estratégia de acolhimento dos refugiados, uma vez que a efetiva garantia dos direitos dos refugiados poderá ser garantida a um nível local. Mais do que uma integração no "todo nacional", os refugiados são integrados numa "comunidade local", sendo estes laços de proximidade essenciais para o sucesso deste programa.

Mesmo considerando que os programas de integração têm um cariz nacional e utilizam verbas nacionais ou comunitárias, a sua aplicabilidade dá-se a um nível local, sendo necessário integrar as comunidades de acolhimento neste processo, principalmente com programas de formação visando a aceitação das diferenças culturais e religiosas, bem como sensibilizar as populações para os riscos e os perigos vividos pelas populações refugiadas.

Nesse sentido, diversas medidas foram adotadas para ajudar no processo de integração dos refugiados, nomeadamente os cursos organizados pela PAR para as pessoas envolvidas no processo de contacto com os refugiados e que abrangiam domínios como o diálogo inter-religioso, a ética, a alimentação ou a cultura ${ }^{32}$. Este apoio tem de ser acompanhado pela disponibilização de habitação condigna aos refugiados e apresentação de um projeto viável e coerente de integração na sociedade portuguesa.

A integração de refugiados em pequenas vilas tem sido um dos argumentos utilizados pelos refugiados para salientar as dificuldades de integração. Em

\footnotetext{
32 Sobre o apoio da PAR ver: <http://www.refugiados.pt/>. Acesso em: 14.08.2017.
} 
2016 o projeto-piloto "Residência Paz" acolheu os primeiros 20 refugiados na vila de Penela (Coimbra), sendo que $40 \%$ acabaram por abandonar o país para destinos como a Alemanha ou a Holanda. A mesma situação é evidenciada em outros concelhos como Mangualde, mas também em Oeiras e Lisboa, o que permite verificar que no caso português não se trata apenas do local específico, mas da possibilidade de outras ofertas em "destinos mais atrativos" na U.E.

Esta questão imbrica diretamente com um outro fenómeno característico das sociedades europeias: a crise demográfica e a falta de mão de obra em diversos sectores, sendo que podemos equacionar se no caso português o interesse em repovoar o interior através do programa de acolhimento de refugiados se sobrepõe ao superior interesse dos refugiados, principalmente ao nível das efetivas oportunidades de integração disponibilizadas nos grandes centros urbanos.

Não será a integração facilitada em destinos com uma forte presença imigrante e caracterizada pela diversidade cultural? Qual o grau de liberdade e autonomia dos refugiados neste processo? Ou pressupomos que a atribuição do estatuto de refugiado implica uma "aceitação das condições de acolhimento", colocando os refugiados numa espécie de "prisão de solidariedade"?

O objetivo último deste processo de integração passa por garantir as condições para os refugiados se transformarem numa parte funcional da sociedade, detentores dos mesmos direitos e das mesmas obrigações que as populações nacionais ${ }^{33}$.

A abertura de diversos Estados em acolher mais refugiados parte de uma premissa dupla, a defesa intransigente dos direitos humanos e a necessidade que diversos países europeus demonstram de rejuvenescimento da sua população. No entanto, a localização geográfica de Portugal, bem como as melhores contrapartidas sociais e financeiras associadas ao estatuto de refugiado concedidas por outros Estados tem colocado o nosso país no final da lista das preferências dos refugiados. Outro dos pontos centrais prende-se com a disponibilização gratuita de cursos de língua e cultura portuguesa de modo a facilitar o processo de integração, sendo que o reduzido conhecimento sobre a realidade portuguesa da maioria dos refugiados implica um esforço adicional na apresentação das potencialidades e características do país. No entanto, face às diferenças intrínsecas a cada realidade, o processo de aprendizagem é moroso e longo, criando uma sucessão de barreiras à integração.

Esta recetividade nacional no acolhimento de refugiados acaba por existir sob um manto de invisibilidade, nomeadamente na base de dados do

\footnotetext{
${ }_{33}$ JUZWIACK, Teressa, MCGREGOR, Elaine, SIEGEL, Melissa. Migrants and Refugee in Global Cities - The Role of Cities and Businesses. The Hague Process on Refugees and Migration.
} 
Conselho Europeu de Refugiados e Exilados (ECRE) que analisa o processo de acolhimento a refugiados em 20 países, excluindo Portugal da referida lista ${ }^{34}$.

O acolhimento de refugiados em Portugal é centralizado pelo Conselho Português para os Refugiados e pelo Serviço Jesuíta aos Refugiados (SJR), sendo que durante os primeiros seis meses os refugiados são acolhidos nestas instituições e posteriormente recolocados nos diversos municípios e instituições participantes no processo de acolhimento. A centralidade dos serviços do CPR e do SJR em Lisboa condiciona a própria mobilidade dos refugiados, que tendem a permanecer nas áreas próximas, de modo a beneficiar do apoio direto destas instituições.

O processo de integração, como referimos, inclui um curso intensivo de língua portuguesa, que poderá representar um total de 300 horas de aprendizagem, sendo que todas as crianças refugiadas são inseridas no sistema público de ensino. O apoio inicial incide, igualmente, na assistência financeira para a alimentação, transporte e despesas de âmbito pessoal, bem como o acesso aos serviços de saúde e a apoio psicológico caso seja requerido/aconselhado.

O processo de integração é delineado com base num Plano de Integração Personalizado (PIP), aplicado a todos os refugiados na fase inicial de integração. Este plano visa delinear a estratégia de integração, tanto no domínio pessoal e social, como no domínio profissional, garantindo uma via de autonomia no processo de integração.

Com base nos dados da Rede Europeia de Recolocação os pontos fortes da estratégia nacional incidem sobre o papel das organizações não-governamentais, num esforço da sociedade civil na gestão deste processo, bem como o apoio profissional disponibilizado na primeira etapa de integração e os níveis de recetividade da sociedade portuguesa ao acolhimento de refugiados ${ }^{35}$. Da mesma análise salientam-se os desafios e as maiores dificuldades registadas, nomeadamente a morosidade de análise dos pedidos de asilo, bem como lacunas ao nível da ligação entre a estrutura governamental e as estruturas locais e criação de ofertas de emprego para os refugiados. Importa referir que os níveis de desemprego registados em Portugal, acima da média comunitária, constituem um dos entraves a uma integração plena.

Um dos problemas centrais incide sobre a questão da habitação, face à pressão imobiliária existente nos grandes centros urbanos. No caso português esta pressão é ainda mais acentuada pelo crescimento exponencial do turismo em Lisboa e no Porto, bem como pelo aumento do valor médio das habitações. Nesse sentido, o caminho tem sido procurar acolher os refugiados em outras regiões do país, onde a disponibilidade do alojamento municipal poderá ser maior.

\footnotetext{
${ }^{34}$ Disponível em: <http://www.asylumineurope.org/reports>. Acesso em: 15.08.2017.

${ }^{35}$ Sobre esta análise ver: <http://www.resettlement.eu/country/portugal > . Acesso em: 16.08.2017.
} 
Qualquer processo de integração deve ter por base o efetivo envolvimento dos refugiados na comunidade nacional, evitando a criação de enclaves segregados que coloquem em causa o processo de acolhimento. A ausência de forças políticas de extrema-direita com forte apoio eleitoral em Portugal, bem como de grupos opositores a este fluxo de refugiados constitui uma mais-valia no caso nacional, permitindo aos atores políticos desenvolver programas de integração que beneficiam da aceitação da maioria da população. Por outro lado, o facto de Portugal apresentar um nível de segurança significativa, sem registo de atentados terroristas, evita qualquer correlação negativa entre o fluxo de refugiados e as condições de segurança, tal como se pode observar em outros Estados.

Esta abertura do país não resolve o problema das preferências dos refugiados por Estados do centro e norte da Europa, onde as redes de apoio e muitas vezes familiares estão já edificadas. Considerando a livre circulação no espaço europeu torna-se inviável controlar os movimentos dos refugiados, pelo que o caminho terá de ser sempre o reforço das condições de acolhimento para garantir uma integração efetiva dos refugiados na comunidade nacional.

\section{Notas finais}

Portugal tem sido um dos Estados europeus mais recetivos a acolher refugiados (a maioria originária da Síria, do Iraque, da Eritreia e da República Centro Africana), tendo demonstrado interesse em receber mais do dobro da quota inicialmente prevista. Perante um cenário de violação de direitos fundamentais, a comunidade nacional tem demonstrado um grau de aceitabilidade elogiado por diversas organizações internacionais.

No entanto, a morosidade do processo de distribuição dos refugiados ao abrigo do programa europeu de recolocação tem impedido o cumprimento efetivo das quotas atribuídas a Portugal. Este processo é ainda dificultado pelo reduzido número de refugiados a demonstrar interesse em serem acolhidos em Portugal, demonstrando uma preferência por países do norte e do centro da Europa, com comunidades de refugiados já estabelecidas e um conjunto de valências de integração mais estruturadas.

No caso português, a par do que se verifica em grandes centros urbanos europeus, a maior dificuldade consiste em disponibilizar habitação para os refugiados, sendo que a estratégia seguida incidiu sobre a disponibilização de habitação municipal em todo o território nacional. Por outro lado, num cenário de recuperação económica, importa assegurar após o período de integração inicial a inserção dos refugidos no mercado de trabalho, pelo que é crucial uma validação das competências e formação de cada refugiado, no sentido de maximizar o seu contributo para o tecido social português. 
Considerando as atuais taxas de natalidade no espectro europeu, o fluxo de refugiados e da imigração em geral pode constituir uma oportunidade para a renovação de gerações, considerando a sustentabilidade do modelo social europeu e a carência de mão de obra em diversos sectores. Este cenário é facilitado em sociedades onde o preconceito e a discriminação para com os estrangeiros não são evidentes, numa defesa da multiculturalidade e de sociedades multiétnicas.

Embora o atual fluxo de refugiados produza um forte impacto cultural, económico e social na sociedade europeia, o imperativo da defesa dos direitos humanos e da vertente solidária europeia sobrepõe-se a qualquer política restritiva. O caminho passa pela simplificação dos processos de concessão de asilo e por políticas de integração mais eficazes, focadas nas necessidades dos refugiados e na capacidade de acolhimento das sociedades nacionais.

\section{Bibliografia}

ADELMAN, Howard. The Refugee Crisis. Refuge, v. 2, n. 5, 1983, p. 1-3.

BARROS, Aidil; LEHFELD, Neide. Fundamentos de Metodologia Científica. São Paulo: Makron Books, 2007.

FERNANDES, Carlos Augusto. Do asilo diplomático. São Paulo: Saraiva, 1983.

CHIMNI, Bhupinder. The birth of a "discipline": From refugee to forced migration studies. Journal of Refugee Studies, v. 22, n. 1, 2009, p. 11-29.

GUILD, Elspeth; COSTELLO, Cathryn; GARLICK, Madeline; MORENO-LAX, Violeta. The 2015 Refugee Crisis in the European Union. CEPS Policy Brief, n. 332, 2015.

JUBILUT, Liliana Lyra. O Direito internacional dos refugiados e a sua aplicação no orçamento jurídico brasileiro. São Paulo: Método, 2007.

JUZWIACK, Teressa; MCGREGOR, Elaine; SIEGEL, Melissa. Migrants and Refugee in Global Cities - The Role of Cities and Businesses. UNU-MERIT, 2014.

LISOWSKI, Telma. A Apatridia e o "Direito a ter Direitos": Um Estudo sobre o Histórico e o Estatuto Jurídico dos Apátridas. Revista Jurídica da Procuradoria Geral do Estado do Paraná, n. 3, 2012, p. 109-134,. Disponível em: <http:// www.pge.pr.gov.br/arquivos/File/Revista_PGE_2012/Artigo_4_A_Apatridia. $\operatorname{pdf}>$.

LOCKE, John. Segundo tratado sobre o governo civil: ensaio sobre a origem, os limites e os fins verdadeiros do governo civil - e outros escritos. Petrópolis, RJ: Vozes, 1994.

MARRUS, Michael. The Forty Years' Crisis: Refugees in Europe, 1919-1959 Conference. 2010. Disponível em: <http://backdoorbroadcasting.net/2010/09/ the-forty-years-crisis-refugees-in-europe-1919-1959/> . Acesso em: 22.07.2017.

MASON, Elisa. Forced Migration Studies: Surveying the Reference Landscape. Libri, v. 50, n. 4, 2000, p. 241-251. 
METCALFE-HOUGH, Victoria. The migration crisis? Facts, challenges and possible solutions. A policy brief. 2015. Disponível em: <www.Odi.org>. Acesso em: 10.06.2017.

MORÊX, Francielli. O Refúgio e a Questão da Identificação Oficial dos Refugiados no Brasil. Revista Direitos Fundamentais \& Democracia, v. 5, 2009, p. 1-23.

PIERIN, Andreza Renata Hillani. Refugiados no mundo contemporâneo: Breves considerações. 2009. Disponível em: <http://www.ceaf.mp.pr.gov.br/arquivos/ File/Monografias/Andreza_Renata_Hillani_Pierin.pdf >. Acesso em: 08.06.2017.

SAMPAIO, Vera. Uma política Europeia para as migrações? In VIII Congresso de Português de Sociologia. 40 anos de Democracias: progressos, contradições e prospectivas. Lisboa: Associação Portuguesa de Sociologia, 2014, p. 1-14. Disponível em: <www.aps.pt/viii_congresso/VIII_ACTAS/VIII_COM0934.pdf>. Acesso a 19.07.2017.

SOUSA, Lúcio. A Crise Global de Refugiados: (In)visibilidade e memória das migrações forçadas. In BACKSTROM, Bárbara; COSTA, Paulo; ALBUQUERQUE, Rosana; SOUSA, Lúcio (orgs.). Migrações e Diversidades Interculturais - Políticas de Igualdade e Inclusão: Reflexões e Contributos I. Lisboa: CEMRI, Universidade Aberta, 2016.

UNHCR. Global Trends. Forced displacement in 2016. 2016. Disponível em: $<$ http://www.unhcr.org/statistics/unhcrstats/5943e8a34/global-trends-forceddisplacement-2016.html>. Acesso em: 22.10.2017.

Recebido para publicação em 31.08.2017

Aceito para publicação em 20.10.2017

Received for publication in August 315t, 2017 Accepted for publication in October $20^{\text {th }}, 2017$

ISSN impresso 1980-8585

ISSN eletrônico 2237-9843

http://dx.doi.org/10.1590/1980-85852503880005103 